\title{
Findings About Events or Interventions Supplemental Qualifiers Dataset
}

National Cancer Institute

\section{Source}

National Cancer Institute. Findings About Events or Interventions Supplemental Qualifiers

Dataset. NCI Thesaurus. Code C147212.

A dataset containing supplemental information, specifically non-standard variables, to

parent records in the findings about events or interventions domain. 